\title{
Pelatihan Pertunjukan Wayang Berorientasi Multilevel Generasi
}

\author{
Junaidi \\ Jurusan Pedalangan, Fakultas Seni Pertunjukan \\ Institut Seni Indonesia Yogyakarta \\ Jalan Parangtritis Km 6,5, Sewon, Bantul, Daerah Istimewa Yogyakarta 55188 \\ No.Tlp.: +6282133723891,E-mail: junaidi.skar@yahoo.com
}




\title{
Pelatihan Pertunjukan Wayang Berorientasi Multilevel Generasi
}

\author{
Junaidi \\ Jurusan Pedalangan, Fakultas Seni Pertunjukan \\ Institut Seni Indonesia Yogyakarta \\ Jalan Parangtritis Km 6,5, Sewon, Bantul, Daerah Istimewa Yogyakarta 55188 \\ No.Tlp.: +6282133723891,E-mail: junaidi.skar@yahoo.com
}

\begin{abstract}
Abstrak
Latar belakang masalah yang mendasari kegiatan ini adalah seniman dalang belum memahami dan menguasai bidang seni wayang untuk format masyarakat kekinian yang berorientasi multilevel generasi dan multifungsi yang salah satunya untuk media pelestarian budaya dan Pendidikan nasional. Oleh karena itu, solusi yang diberikan adalah mengajarkan pengetahuan seni wayang beserta teknik penyajiannya bagi seniman multiusia di wilayah Dusun Kaliurang Timur. Tempat kegiatan di rumah Mbah Carik Kaliurang Timur atau Pendapa Budaya Kaliurang. Penyuluhan ini diikuti sejumlah 24 peserta, terdiri atas 1 orang pemain wayang usia tua, 1 orang pemain wayang usia muda, dan 22 pengrawit. Hasil yang telah dicapai adalah munculnya model pertunjukan wayang multilevel dan kondisional, yakni pementasan untuk dalang muda dan dewasa dengan mengambil cerita sekitar wilayah, yaitu Cerita Gunung Merapi dan Tlaga Putri.
\end{abstract}

Kata kunci: dalang, seni wayang, wayang multilevel

\section{Shadow Puppet (Wayang) Performance Training Oriented for Multilevelled Generation}

\section{Abstract}

The core problem that initiates this training is the incompetence of dalang who have not understand and master the shadow puppet arts in more contemporary form to conform to recent society's preferences. Arts now are targeted to multiple levels of generations and to be multi-functional in its usage as a medium of arts conservation and national education. Hence, the proposed solution is to teach the knowledge of shadow puppet arts along with its technique to artisans across age and generations in East Kaliurang village. The training was conducted in East Kaliurang village head's house or Kaliurang Cultural gazebo. Twenty-four people participated in this training, with 1 senior shadow puppet performer, 1 younger shadow puppet performer, and 22 gamelan musicians. Results gained is the achieved multilevel shadow puppet arts model that conditionally conforming to older and younger dalang with stories set in familiar areas, which is surrounding the Merapi Volcano and Tlaga Putri.

Keywords: dalang, shadow puppet art, multilevel shadow puppet 


\section{PENDAHULUAN}

Di Dukuh Kaliurang Timur, Hargobinangun, Pakem, Sleman, Daerah Istimewa Yogyakarta terdapat sekelompok seniman dalang beserta peralatan wayang dan gamelannya. Dahulu kegiatan seni pewayangan di wilayah ini cukup semarak baik bersifat pertunjukan maupun pelatihan, tetapi dua tahun terakhir ini aktivitas kegiatan seni pewayangan mengalami kesurutan bahkan dikatakan mati tanpa kegiatan sehingga fasilitas wayang dan gamelan tidak dioperasionalkan. Wayang dua peti tampak tertutup rapat tanpa tahu di dalamnya bagaimana boneka wayangwayangnya. Begitu pula dua perangkat gamelan perunggu laras slendro pelog hanya tampak ditumpuk dan terselimuti oleh debudebu yang tebal.

Kondisi ini terjadi akibat tiadanya langkah pewarisan kepada generasi mudanya sehingga warisan seni yang ada tidak bisa diwarisi oleh generasi penerusnya. Disimak dari pernyataan para generasi muda terdapat keinginan untuk melaksanakan kegiatan seni wayang warisan dari leluhurnya tersebut, tetapi format filosofi dan teknik estetikanya bersifat tradisional yang secara komunikasi cerita, bahasa, pergerakan, dan musikalnya sulit diterima oleh generasi mudanya sehingga perlu diberikan format wayang kekinian. Hal ini dimengerti oleh para sesepuh, tetapi mereka tidak memiliki ilmu untuk mewariskan seni wayang yang bersifat kekinian. Oleh karena itu, kepala daerah pedukuhan di Kaliurang Timur melakukan koordinasi dengan Lembaga Pengabdian Masyarakat ISI Yogyakarta untuk memberikan penyuluhan seni wayang sebagai wahana penghidupan kembali dan pelestarian seni pada masa sekarang yang berorientasi pada pencakupan multigenerasi.

Permasalahan yang ada adalah belum memahami dan menguasai bidang seni wayang untuk format masyarakat kekinian yang berorientasi multilevel generasi dan multifungsi salah satunya untuk media pelestarian budaya dan pendidikan nasional. Dari permasalahan tersebut solusi yang ditawarkan adalah mengajarkan pengetahuan seni wayang beserta teknik penyajiannya bagi seniman multiusia di wilayah dusun Kaliurang Timur. Pembelajaran pengetahuan dilakukan selama dua kali pertemuan, sedangkan penyajian wayang dilatihkan selama sembilan kali pertemuan. Sebagai evaluasi dilakukan pementasan seni wayang satu kali pelaksanaan bagi seniman dalang multilevel hasil dari penyuluhan. Tujuan kegiatan ini adalah meningkatkan kemampuan dalam bidang dan teknik mayang agar sesuai dengan tuntutan zaman dan masyarakat masi kini, tetapi tidak meninggalkan kaidah ilmu pedalangan beserta estetikanya.

\section{METODE PENGABDIAN}

Metode yang digunakan adalah ceramah dan workshop tentang pertunjukan wayang multilevel untuk para pemain wayang dan karawitan di wilayah Kaliurang Timur. Ceramah dilakukan dengan cara lisan kepada peserta, sedangkan workshop dilakukan dengan cara kerja melakukan pertunjukan dengan contoh penyuluh kemudian diikuti oleh peserta.

\section{HASIL DAN PEMBAHASAN}

Penyuluhan ini diikuti sejumlah 24 orang peserta, terdiri atas 1 orang pemain wayang usia tua, 1 orang pemain wayang usia muda, dan 22 pengrawit. Tempat kegiatan berada di Rumah Mbah Carik Kaliurang Timur atau Pendapa Budaya Kaliurang. Materi kegiatan meliputi: (1) penyampaian pengetahuan seni wayang secara umum; (2) penyampaian tentang wayang multi level untuk tiga generasi, yaitu anak, remaja, dan dewasa; (3) pelatihan membuat dan menyajikan lakon dalam pakeliran bagi dalang multiusia; (4) 
pelatihan membuat dan menyajikan narasi atau catur dalam pakeliran bagi dalang multiusia; (5) pelatihan membuat dan menyajikan gerak atau sabet dalam pakeliran bagi dalang multiusia. Sabet adalah semua bentuk penampilan wayang, meliputi cepengan, bedholan, metonan, tancepan, solah, dan entas-entasan (Junaidi, 2014:9); (6) pelatihan membuat dan menyajikan lagu atau gendhing dalam pakeliran bagi dalang multiusia. Gending adalah istilah lagu dalam musikal gamelan, sedangkan gending wayangan, yaitu gending-gending yang biasa digunakan untuk mendukung pertunjukan wayang (Supanggah, 2009:133). Gending harus mungkus (membingkai), nglambari (ilustrasi), dan nyawiji (menyatu) (Waridi, 2005); (7) pelatihan membuat dan menyajikan nyanyian atau sulukan dalam pakeliran bagi dalang multiusia; (8) pelatihan membuat dan menyajikan nyanyian atau tembang dalam pakeliran bagi dalang multiusia; (9) pelatihan membuat dan menyajikan pakeliran bagi dalang multiusia, dengan masing-masing satu cerita berurutan dalam lakon banjaran (muda dan dewasa); dan (10) evaluasi dalam bentuk naskah pementasan, bagi dalang multilevel usia dan multilevel cerita.

Materi pertama adalah tentang format wayang untuk dalang multilevel. Dalang merupakan salah satu profesi yang semula ditekuni oleh orang berusia dewasa atau tua, tetapi dalam perkembangannya diminati oleh anak dan remaja atau generasi muda, ditandai dengan munculnya dalang anak dan remaja di berbagai wilayah Indonesia sehingga perlu diberikan alat boneka wayang yang sesuai dengan ukuran fisik dan jiwanya. Untuk itu, perlu dilakukan rancangan format wayang untuk dalang multilevel ini mengacu pada konsep tingkat usia dan pendidikan, yakni memiliki sifat bertingkat/berjenjang dan meningkat/menambah. Bertingkat, menyesuaikan dengan tingkatan usia dan pendidikan di Indonesia, yakni dimulai dari level usia anak-anak atau pada jenjang Pendidikan Anak Usia Dini/Taman KanakKanak (PAUD/TK), ditingkatkan pada level anak atau pada jenjang Sekolah Dasar/Madrasah Ibtidaiyah (SD/MI), ditingkatkan pada pada level remaja awal atau pada jenjang Sekolah Menengah Pertama/Madrasah Tsanawiyah (SMP/MTs), ditingkatkan pada level remaja penuh atau pada jenjang Sekolah Menengah Atas/Sekolah Menengah Kejuruan/Madrasah Aliyah (SMA/SMK/MA), dan diakhiri pada level muda dan dewasa atau pada jenjang Pendidikan Tinggi (PT). Dengan demikian, muncul persamaan jenjang antara wayang dengan pendidikan, sehingga media yang dirancang bisa menyesuaikan dengan tingkatan usia dan pendidikan (trep/cocok).

Wayang untuk dalang bersifat transformasi, yakni dibuat multilevel ukuran dan berupa boneka tiruan manusia, raksasa, dewa, makhluk halus, flora, peralatan, dan fauna. Wujud wayang secara ikonografi menandai peranan, usia, kedudukan, kelamin, karakter, dan suasana hati, maka wujud wayang multilevel tersebut disesuaikan dengan tingkat perkembangan fisik dan jiwa peserta didik, yakni bersifat multilevel (level anak, level remaja, dan level dewasa). Boneka wayang merupakan totalitas dari kumpulan antarunsur, yaitu tatahan/pahatan, sunggingan/pewarnaan, dan gapitan/pembingkaian dipadu menjadi satu dalam boneka yang dapat dijadikan sebagai figur dalam suatu cerita atau lakon sehingga secara teknik dan estetik dapat digerakkan keindahan tata ruang anatomi, busana, dan aksesorisnya. Sketsa wujud wayang merupakan transformasi dari suatu bentuk wayang tradisi, yaitu ekspresif dekoratif tradisional dan ekspresif dekoratif humoris karikatural, tetapi menurunkan tingkat kerumitan teknik dan estetis sehingga mudah dipahami oleh siswa PAUD sampai PT. 
Perbedaan tata aturan dan sifat dari ketiga unsur dalam wayang tersebut dapat direlasikan menjadi keterkaitan tingkatan sehingga bisa saling mendukung dan mengatur diri pada level masing-masing. Dengan model kaitan bertingkat, model wayang pendidikan dapat dipelajari sejak level awal, level dasar, level menengah, dan level tinggi. Gambar 1, 2 dan 3 adalah contoh wujud wayang multilevel.

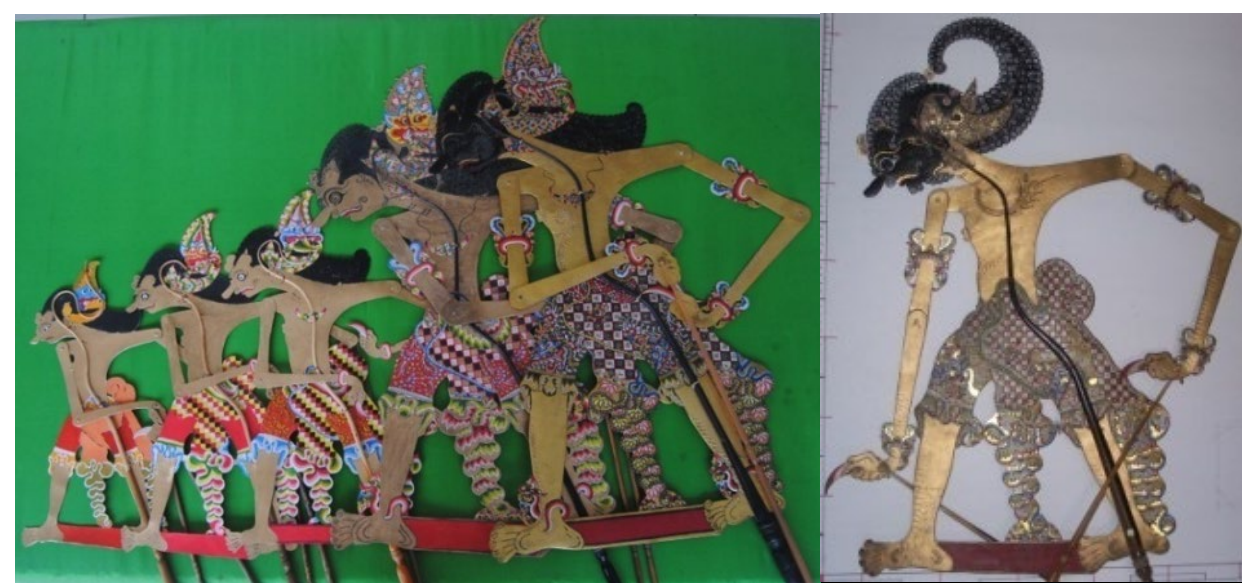

Gambar 1 Contoh wujud wayang multilevel, yaitu Bima berekspresi anak-anak (kiri), anak (kedua dari kiri), remaja awal (ketiga dari kiri), remaja akhir (keempat dari kiri), muda (kelima dari kiri), dan dewasa bernamaWerkudara (kanan) (Foto: Junaidi, 2016)

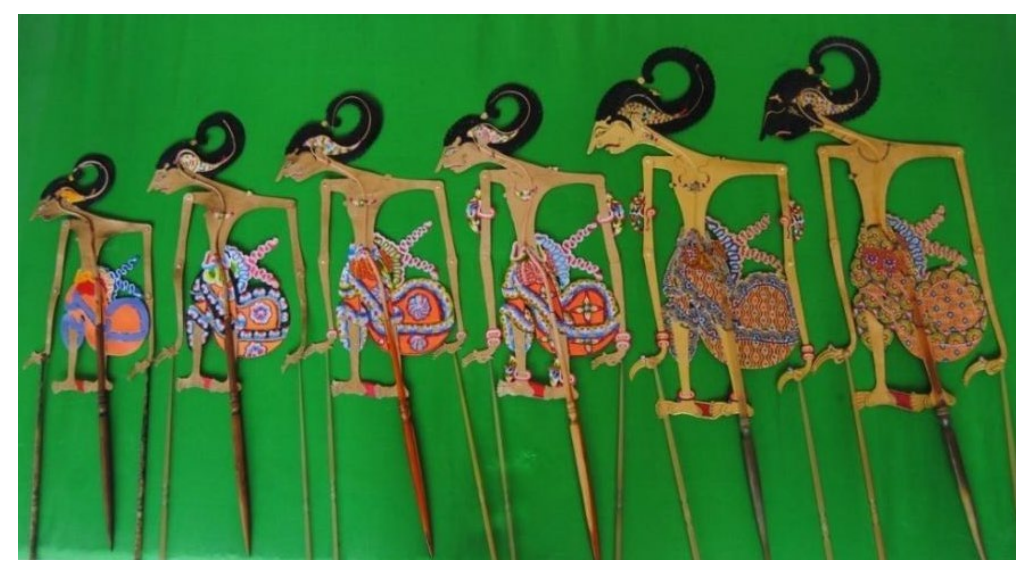

Gambar 2 Contoh wujud wayang multilevel, yaitu Arjuna berekspresi anak-anak (kiri), anak (kedua dari kiri), remaja awal (ketiga dari kiri), remaja akhir (keempat dari kiri), muda (kelima dari kiri), dan dewasa bernama Janaka(kanan)

(Foto: Junaidi, 2016) 

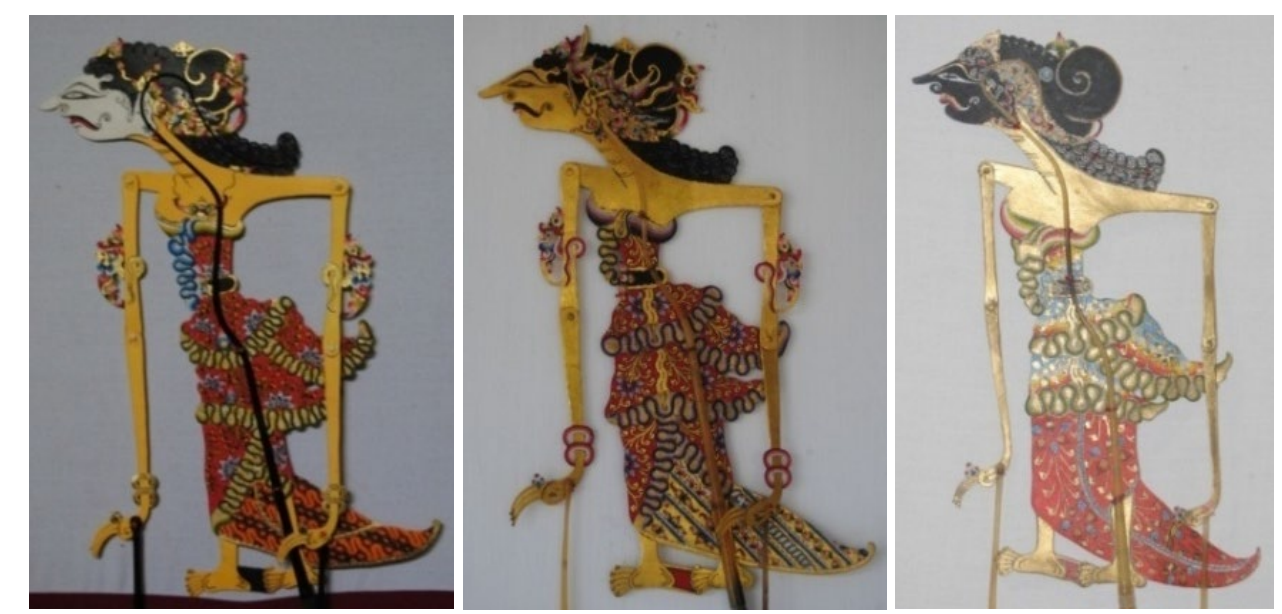

Gambar 3 Contoh wujud wayang putri bernama Srikandi divisualkan masih anak (kiri), remaja (tengah), dan dewasa (kanan)

(Foto: Junaidi, 2016)

Di samping itu, dalam setiap jenis bersifat pengaturan diri karena memiliki rentangan ukuran yang berbeda-beda sesuai dengan proporsi tubuhnya. Secara urutan terdapat tujuh macam ukuran, yaitu (1) ukuran paling besar/sakbutaraton, (2) ukuran besar/ sakwerkudara, (3) ukuran magak/sakgatutkaca, (4) ukuran tanggung/sakarjuna, (5) ukuran sedang/sakbimanyu, (6) ukran kecil/sakputrèn, dan (7) ukuran paling kecil/sakbayèn. Perbedaan ukuran ini menyesuaikan dengan perkembangan fisik peserta didik yang mengalami perkembangan dari kecil menjadi besar (postur tubuh) atau pendek menjadi panjang (tinggi badan), yakni dari ukuran fisik sangat kecil (anak-anak), kecil (anak), sedang (remaja awal), tanggung (remaja penuh), hingga besar (dewasa-tua).

Hasil yang telah dicapai adalah munculnya model pertunjukan wayang multilevel dan kondisional, yakni pementasan untuk dalang muda dan dewasa dengan mengambil cerita sekitar wilayah, yaitu Cerita Gunung Merapi dan Tlaga Putri. Cerita Gunung Merapi mengisahkan terbentuknya Gunung Merapi yang semula berasal dari perapian atau besalèn pembuatan senjata milik Empu Ramayadi yang ditimbun oleh para dewa, sedangkan cerita Tlaga Putri mengisahkan kejadian suatu telaga yang dihuni oleh makhluk halus, seorang putri cantik berada di kawasan Kaliurang Timur. Kedua kisah tersebut ditampilkan dalam suatu pertunjukan oleh masyarakat setempat.

\section{SIMPULAN}

Kegiatan penyuluhan di Dukuh Kaliurang Timur ini menghasilkan format karya seni wayang, tari, dan karawitan, dengan kisah spesifik berkaitan dengan terjadinya Gunung Merapi dan Tlaga Putri. Kedua kisah tersebut merupakan legenda masyarakat di sekitarnya sehingga dapat mengangkat potensi daerah dengan memberdayakan seniman dan seniwati di wilayah Kaliurang Timut. Selanjutnya, perlu dilakukan kegiatan Pengabdian kepada Masyarakat sejenis seperti P3Wilsen dan Pembianaan UMKM agar berkelanjutkan dan masyarakat mendapatkan nilai material dan spiritual dari kegiatan berkesenian. Dengan demikian, kegiatan seni di wilayah Kaliurang Timur ini bisa hidup dan berkembang, bahkan bisa berdampak pada penguatan ideologi dan ekonomi bagi masyarakat setempat. 


\section{SARAN}

Saran yang diberikan untuk pelaksanaan pengabdian yang semakin baik antara lain perlu dilakukan kegiatan penerus agar keberlanjutan bisa berjalan, perlu dukungan pemerintah setempat dan Kabupaten Sleman guna memetakan dan memajukan seni yang berada di wilayah masing-masing di bawah pemerintahan Kabupaten Sleman, dan perlu sinergitas dengan kegiatan lain untuk menguatkan posisi seni di masyarakat.

\section{UCAPAN TERIMA KASIH}

Penulis mengucapkan terima kasih kepada Lembaga Penelitian dan Pengabdian Masyarakat Institut Seni Indonesia Yogyakarta yang telah memberi dukungan terhadap keberhasilan pengabdian ini.

\section{DAFTAR PUSTAKA}

Junaidi. (2014). “Modul Pembelajaran Seni Pedalangan Gaya Yogyakarta untuk Guru Sanggar”. Makalah pada pelatihan seni pedalangan gaya Yogyakarta oleh PEPADI dan Yayasan TOTAL, 22-24 di Sanggar Seni Pondok Tingal, Borobudur, Magelang, Jawa Tengah.

Supanggah, Rahayu, (2009). Bothèkan Karawitan II: Garap. Surakarta: Program Pascasarjana bekerja sama dengan ISI Press Surakarta.

Waridi. (2005). Karawitan Wayang Kulit Purwa Gaya Surakarta. Jakarta: Sekretariat Nasional Pewayangan Indonesia. 
